\title{
Analysis on the Effect of Empennage Leeboards Model on the Aerodynamic Characteristics of the FSAE Race Car
}

\author{
Xia Tianzha, Li Yaoping, Liu Zexuan
}

Faculty of Transportation Engineering, Kunming University of Science and Technology, Kunming, China

Keywords: FSAE race car; aerodynamics; empennage leeboards; CFD

\begin{abstract}
Based on the 2017 Formula Student Electric race car of KMUST, racing team of Kunming University of Science and Technology built entity models by CATIA, designed and optimized the combined wings of the race car spoiler by STAR-CCM+, comparing with the model of leeboards on different "gills" area, "gill" number and notch at the back edge by the Orthogonal experiment. The results show the aerodynamic efficiency of the rear wing is improved obviously through the leeboards modeling optimization, in which the drag coefficient (cd) is reduced by $13.75 \%$; the lift-to-drag ratio is increased by $6.71 \%$.
\end{abstract}

\section{Introduction}

Founded by the International Academy of Automotive Engineering, Formula Society of Automotive Engineers is a formula racing competition for college students all over the world, which requires excellent performance in acceleration, braking, handling stability and durability. After years of development, the chassis and power system optimization can no longer meet the FSAE racing pursuit of higher performance. Under the condition that the maximum output power of the battery must not exceed $80 \mathrm{KW}$, it is very important to use the aerodynamics kit to produce proper drag to enhance the grip of the tire and to study the effect of the empennage leeboards modeling on the aerodynamic efficiency of theempennage.

In the design of the combined wing of the empennage of FSAE, the attack angle of the wing is regarded as the focus of optimization, and the effect of the aerodynamic characteristics of the empennage leeboards modeling is less considered. Literature [1] explores the influence of the shape of FSAE car body on the aerodynamic characteristics of the car. Literature [2] the starting point is the relationship between the position of the Pressure Center and the center of gravity of the car. A preliminary analysis of the high speed stability and steering characteristics of a racing car equipped with an aerodynamics kit has been made. [3] A set of matching aerodynamics kits, including front wings, empennages and diffusers, has been designed. The aerodynamic efficiency of the aerodynamics kit is verified in the paper .In reference [4], the distribution of pressure and velocity around the vehicle is analyzed, and the performance of the aerodynamics kit is studied.In reference [5], six types of NACA4412 airfoil prototypes, such as changing the starting position of the modified airfoil, the thickness of the tail edge and the shape of the smooth curve, are numerically simulated.Found that the modified airfoil can effectively improve the lift coefficient and the lift / drag ratio of the airfoil in a certain range of angles of attack. The empennage of FSAE racing car is studied in reference [6]. CFD analysis and comparison of different airfoil combinations, attack angle of wing, height above ground, and number of wings show that the airfoil with larger curvature and thicker wing body will produce a larger number of wings.In reference [7], the angle of attack of the wing is taken as the focus of optimization, and the FLUENT is used to optimize the design of the combined wing. In reference [8], the effects of different combined wing shapes on the aerodynamic efficiency of racing cars were studied. Reference [9] based on the design and optimization of the empennage of FSAE racing car based on CFD, the paper compares the no leeboards, the smaller leeboards and the larger leeboards, and concludes that the larger end plate has a positive effect on the lower pressure of the lift empennage.

This paper will focus on the analysis and optimization of the the model of leeboards on different "gills" area; "gill" number and notch at the back edge based on Navier-Stokes equation (N-S 
equation) and $\kappa-\varepsilon$ turbulence model. The solid model is built with CATIA, the finite element analysis is carried out by STAR-CCM. And the aerodynamic characteristics of the empennage of electric formula racing car in 2017 season of KMUST team are studied by orthogonal test method.

\section{Establishment of Computational Model}

\subsection{Main wing aileron model}

For the empennage, the size of the wing slot of the combined wing affects the attachment of the airflow to the wing,delays the flow separation. Similarly, when the attack angle of the wing exceeds a critical value, the stall will happend with the increase of attack angle, which will affect the aerodynamic characteristics of the empennage. In order to make the analysis of the aerodynamic characteristics of the empennage more accurate and the empennage have better aerodynamic efficiency it is necessary to determine the design of the main wing and the aileron first. Using STAR-CCM to calculate the selected pilot units, found the best relationship between the main wing, ailerons angle of attack and gap between wings by using one-dimensional search method. The angle of attack of the main wing is $7^{\circ}$, the angle of attack of the aileron is $43^{\circ}$, the vertical length of the gap between wings is $15 \mathrm{~mm}$, the horizontal length of the gap between wings is $50 \mathrm{~mm}$.

\subsection{Geometric dimensions of wing and leeboards}

Limitations between rules: 'Back-end mounting device: From the overlooking map,Any aerodynamics device(such as, Negative lift wing, baseboard, splitter )must satisfy the following conditions: a. Cannot beyond the rear end of the rear wheel $250 \mathrm{~mm}(9.8 \mathrm{in})$.b.If the headrest is adjustable, the aerodynamic device (including the floor) shall not exceed the vertical plane at the last position of the headrest support front after being adjusted to the rear position, excluding any gasket.c. Cannot be wider than the inner side of the rear tire (measured by the center height of the rear wheel).In order to ensure sufficient downward pressure, a large area of wing surface was used.In order to improve aerodynamic performance under regular frame, main wing: wingspan $900 \mathrm{~mm}$, chord length 520mm, aileron: wingspan $900 \mathrm{~mm}$, chord length $260 \mathrm{~m}$. The main wing aileron adopts GOE430 airfoil.leeboards: $880 \mathrm{~mm}$ long and $750 \mathrm{~mm}$ wide, CATIA is used to build 3D model.'

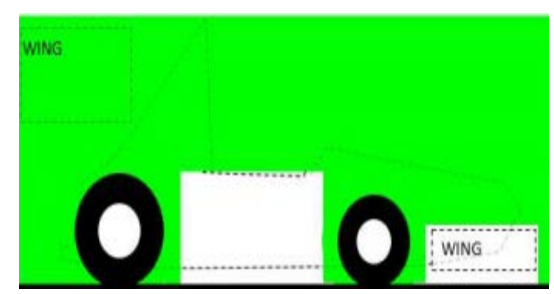

Fig. 1 Restrictions on the installation position and size of the empennage in fsae rules

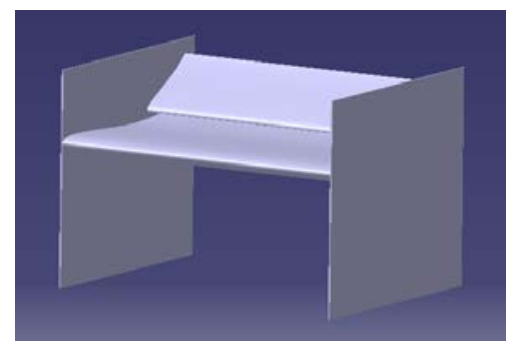

Fig. 2 Empennage’s modeling diagram

\subsection{Overview of the basic theory of CFD simulation}

The air flow characteristics in the radiator and the outflow field of cars and high-speed EMU are essentially fluid flow and heat transfer. The N-S equation is applicable for any complex turbulent flow. [11]The Navier-Stokes equation (N-S equation) and turbulence model are mainly used in CFDs (Computational fluid Dynamics). 


\subsection{1. nave Stokes equation}

Vector form:p $\frac{\mathrm{d}_{\mathrm{v}}}{\mathrm{d}_{\mathrm{t}}}=-\nabla \mathrm{p}+\mathrm{pF}+\mu \Delta \mathrm{v}$ )

In Cartesian coordinates:

$\rho \frac{\mathrm{d}_{\mathrm{u}}}{\mathrm{d}_{\mathrm{t}}}=-\frac{\partial_{\mathrm{p}}}{\partial_{\mathrm{x}}}+\rho \mathrm{X}+\mu \Delta \mu$,

$\rho \frac{\mathrm{d}_{\mathrm{v}}}{\mathrm{d}_{\mathrm{t}}}=-\frac{\partial_{\mathrm{p}}}{\partial_{\mathrm{y}}}+\rho \mathrm{Y}+\mu \Delta \mathrm{v}$

$\rho \frac{\mathrm{d}_{\mathrm{w}}}{\mathrm{d}_{\mathrm{t}}}=-\frac{\partial_{\mathrm{p}}}{\partial_{\mathrm{z}}}+\rho \mathrm{Z}+\mu \Delta \mathrm{w}$

$\Delta$ is Laplacian operator; $\rho$ is the density of fluid; $P$ is the pressure $u / v / w$ is the velocity component at point $(\mathrm{x}, \mathrm{y}, \mathrm{z})$ of the fluid at $\mathrm{t}$ time. $\mathrm{X}, \mathrm{Y}, \mathrm{Z}$ are the components of the external force; The constant $\mu$ is the dynamic viscosity coefficient.[11]

\subsection{2. turbulence model}

Turbulent energy k equation:

$\rho \frac{\mathrm{Dk}}{\mathrm{Dt}}=\frac{\partial}{\partial \mathrm{x}_{\mathrm{i}}}\left[\left(\mu_{\mathrm{i}}+\frac{\mu_{\mathrm{t}}}{\sigma_{\mathrm{k}}}\right) \frac{\partial \mathrm{k}}{\partial \mathrm{x}_{\mathrm{j}}}\right]+\mathrm{G}_{\mathrm{k}}+\mathrm{G}_{\mathrm{b}}-\rho \varepsilon$

turbulent dissipation rate $\varepsilon$ :

$\rho \frac{\mathrm{D} \varepsilon}{\mathrm{Dt}}=\frac{\partial}{\partial \mathrm{x}_{\mathrm{i}}}\left[\left(\mu_{\mathrm{i}}+\frac{\mu_{\mathrm{t}}}{\sigma_{\mathrm{g}}}\right) \frac{\partial \mathrm{k}}{\partial \mathrm{x}_{\mathrm{j}}}\right]+\mathrm{C}_{1 \varepsilon} \frac{\varepsilon}{\mathrm{k}}\left(\mathrm{G}_{\mathrm{k}}+\mathrm{C}_{3 \varepsilon} \mathrm{G}_{\mathrm{b}}\right)-\mathrm{C}_{2 \varepsilon} \rho \frac{\varepsilon^{2}}{\mathrm{k}}$

$\mu_{\mathrm{i}}$ is Laminar viscosity coefficient; $\mu_{\mathrm{t}}$ isTurbulent viscosity coefficient; $\mathrm{G}_{\mathrm{k}}$ is Turbulent kinetic energy generated byLaminar velocity gradient; $\mathrm{G}_{\mathrm{b}}$ is the turbulent kinetic energy generated by buoyancy; $\mathrm{C}_{1 \varepsilon}, \mathrm{C}_{2 \varepsilon}, \mathrm{C}_{3 \varepsilon}, \sigma_{\mathrm{k}}$ and $\sigma_{\mathrm{g}}$ is empirical constant; $\mathrm{C}_{\mu}$ is Turbulence constant.

\subsection{Establishment of computational models}

After drawing the engineering drawing of empennage with CATIA, the aerodynamics simulation analysis is carried out with STAR-CCM software.Establish an outflow field model with a length of $4000 \mathrm{~mm}$ an; awidth of $3000 \mathrm{~mm}$; aheight of $1500 \mathrm{~mm}$ outside the empennage.The boundary conditions: the inlet is a velocity inlet of $50 \mathrm{kphh}$; the outlet is a pressure outlet; the ground is a slipping; and the empennage is a wall boundary.

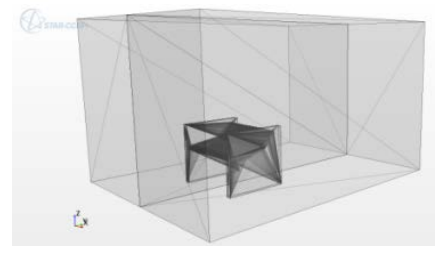

Fig. 3 Establishing fluid domain and grid division in star-ccm+

\section{Leeboards Initial Scheme}

\subsection{Empennage leeboards gill and leeboards edge notch}

FASE leeboards design, referring to F1 car leeboards modeling, mainly adopts two ways to optimize the shape, namely "gill" structure and leeboards edge notch.Explore the aerodynamic characteristics of the empennage in the multi-bend, low average speed, low Reynolds number, non-viscous, incompressible conditions of the FSAE race.

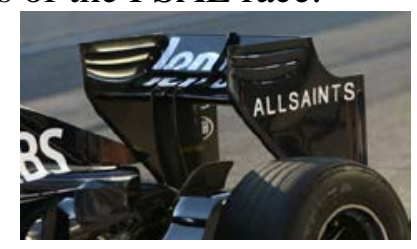

Fig. 4 the empennage of F1

The tip vortex causes the air flowing through the wing to generate a downwash speed and a downward tilt to form a downwash flow. The angle at which the flow is inclined downward, called 
the downwash angle. The downwash speed produced by the vortex of the airfoil is maximum at the two airfoils, decreasing toward the center, and minimum at the center. This is because the air is sticky, the wingtip vortex drives the air around it to rotate together, the more the inner ring, the faster the rotation, the more the outer ring, the slower the rotation. Therefore, the farther away from the airfoil, the smaller the flow rate.

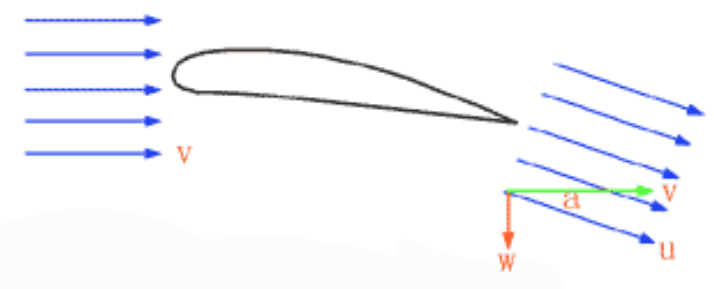

Fig. 5 the downwash velocity of wing profile

Figure 5 shows the downwash speed on a wing profile. Its direction is opposite to the direction in which the plane flies, and its function is to block the advance of the aircraft. It's actually a drag. The downward wash caused by the vortex at the airfoil will cause the lift to drop, and the drag will increase. The main purpose of the leeboards "gill" and leeboards edge notchstructure is to reduce the induced drag caused by the vortex downwash phenomenon in the rear wing in F1. Compared to the FSAE racing combination wing, the main purpose is to reduce the induced drag caused by the vortex downwash phenomenon in the rear wing. The leeboards mainly acts as a insulator between the upper and lower sides of the high pressure zone and the low pressure zone, and prevents the flow of the high pressure region from overturning to the low pressure region, thus destroying the lower pressure difference. The air is flowing upAfter the lower wing surface converges in the rear region of the wing, because of the velocity difference and pressure difference between the two airflow, the two airflow will form a spiral induced vortex after contact, and the vortex will produce drag. This phenomenon is seldom studied in the low speed condition of FSAE, so the initial optimization of the leeboards of FASE racing car is carried out, and the influence of the leeboards modeling on the aerodynamic characteristics of the empannage of FSAE racing car is explored by adding the structure similar to F1.

\subsection{Comparison of the prototype empennage and initial scheme}

The initial scheme (figure 6) design is formed by adding a "gill" structure and a leeboards edge notch to the leeboards (figure 2).Using the CFD method described in the first section, the flow field of the prototype empennage is compared with that of the initial scheme. The results are shown in Table 1.

Table 1 Comparison of aerodynamic characteristics between prototype empennage and initial scheme

\begin{tabular}{llll}
\hline Empennage model & Lift & drag coefficient & Lift-drag ratio \\
& coefficient & & \\
\hline prototype empennage & 2.199 & 0.442 & 5.21 \\
initial scheme & 2.017 & 0.377 & 5.35 \\
\hline
\end{tabular}

From the above table, it can be seen that after the "gill" and the leeboards edge notch form are optimized, the lift coefficient $\mathrm{cl}$ of the initial scheme decreases by $8.3 \%$, the drag coefficient CD decreases by $15.8 \%$, and the rise-to-drag ratio $(\mathrm{cl} / \mathrm{cd})$ increases by $2.7 \%$ compared with that prototype empennage. It can be seen that the optimization of the "gill" and the leeboards edge notch can obviously reduce the drag, but it will lose a part of the lower pressure, and at the same time, it can maintain a higher lift-to-drag ratio. It can be seen that it is feasible to optimize the aerodynamic performance of the empennage by using the above method, and the interaction of the optimization factors and the optimal solution can be further explored. 


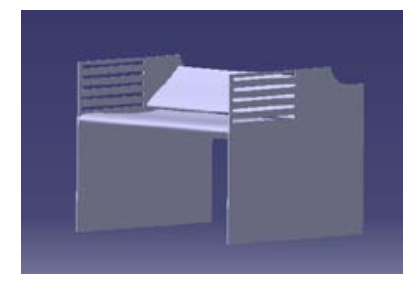

Fig. 6 empennage end Plate Initial

\section{Test Design}

\subsection{Orthogonal test method}

Orthogonal test is an efficient method to solve the optimal, comprehensive comparison and statistical analysis under multi-factor and multi-level conditions. On the premise of minimizing the number of experiments, the main influencing factors can be analyzed and the relationship between the factors can be revealed.

\subsection{Design of test schemes}

The influence factors and the level of the leeboards modeling on the aerodynamic characteristics of the empennage are mainly shown in the parameter table 2 of the horizontal parameter table of the factors.It contains 3 factors, each of which contains 4 levels. For a full trial, we need to test $4^{3}=64$ times, but, if we use the orthogonal test, we just need to test 16 times.

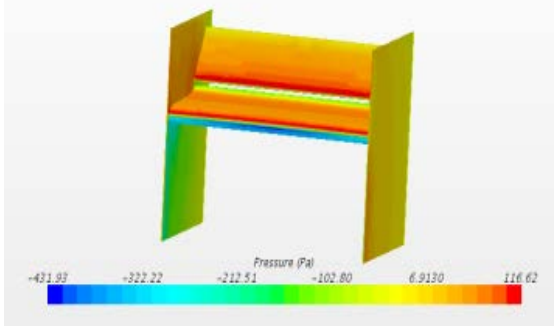

(a) Prototype empennage pressure cloud

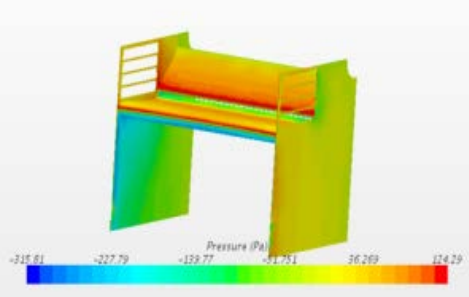

(b) Initial design Pressure Cloud

Fig. 7 test schemes

Considering the structure of "gill", the total area of "gill", the number of "gills" and the effect of the shape of the leeboards edge notch on the aerodynamic characteristics of the empennage, four levels are designed for each factor. The area of "gill" is limited to the area indicated, the number of "gill" is equal and the area of slotted area is equal; the form of leeboards edge notch is shown in (fig. 9).

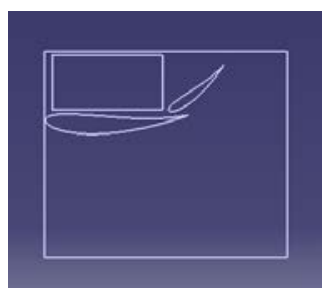

Fig. 8 the limited area of shutter

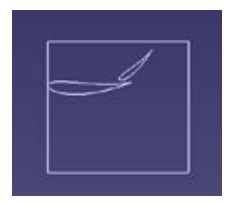

(a)

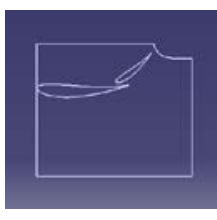

(b)

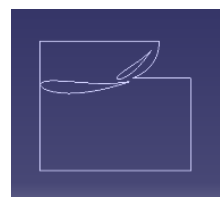

(c)

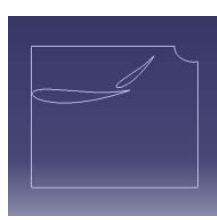

(d)

Fig. 9 the form of leeboards edge notch 
Table 2 orthogonal table of parameter design

\begin{tabular}{cccccccc}
\hline test & $\begin{array}{c}\text { Level } \\
\text { combination }\end{array}$ & $\begin{array}{c}\text { The } \\
\text { of } \begin{array}{c}\text { area } \\
\text { gill }\end{array}\end{array}$ & $\begin{array}{c}\text { the number of } \\
\text { gill (B) }\end{array}$ & $\begin{array}{c}\text { leeboards } \\
\text { edge notch } \\
\text { model(C) }\end{array}$ & $\begin{array}{c}\text { Lift } \\
\text { coefficient }\end{array}$ & $\begin{array}{c}\text { drag } \\
\text { coefficient }\end{array}$ & $\begin{array}{c}\text { Lift-drag } \\
\text { ratio (\%) }\end{array}$ \\
\hline 1 & A1B1C1 & 10000 & 2 & I & 1.832 & 0.426 & 4.300 \\
2 & A1B1C2 & 10000 & 3 & II & 1.870 & 0.402 & 4.651 \\
3 & A1B3C3 & 10000 & 4 & III & 2.056 & 0.368 & 5.586 \\
4 & A1B4C4 & 10000 & 5 & IV & 2.053 & 0.371 & 5.533 \\
5 & A2B1C2 & 30000 & 2 & II & 1.746 & 0.399 & 4.375 \\
6 & A2B2C4 & 30000 & 3 & IV & 1.927 & 0.422 & 4.542 \\
7 & A2B3C1 & 30000 & 4 & I & 1.924 & 0.356 & 5.404 \\
8 & A2B4C3 & 30000 & 5 & III & 2.017 & 0.377 & 5.350 \\
9 & A3B1C3 & 50000 & 2 & III & 1.760 & 0.399 & 4.411 \\
10 & A3B2C4 & 50000 & 3 & IV & 2.013 & 0.386 & 5.215 \\
12 & A3B3C1 & 50000 & 4 & I & 1.721 & 0.407 & 4.228 \\
13 & A4B4C2 & 50000 & 5 & II & 1.783 & 0.424 & 4.205 \\
14 & A4B1C4 & 70000 & 2 & IV & 1.956 & 0.368 & 5.315 \\
14 & A4B2C3 & 70000 & 3 & III & 2.090 & 0.381 & 5.485 \\
15 & A4B3C2 & 70000 & 4 & II & 2.026 & 0.364 & 5.565 \\
16 & A4B4C1 & 70000 & 5 & I & 1.905 & 0.391 & 4.872 \\
\hline
\end{tabular}

Table 3 the data table of orthogonal test

\begin{tabular}{cccccc}
\hline factor & level1 & level2 & level3 & level4 \\
\hline A & The area of gill $(\mathrm{mm} 2)$ & 10000 & 30000 & 50000 & 70000 \\
& B the number of gill & 1 & 2 & 3 & 4 \\
C leeboards edge notch model & I & II & III & IV \\
\hline
\end{tabular}

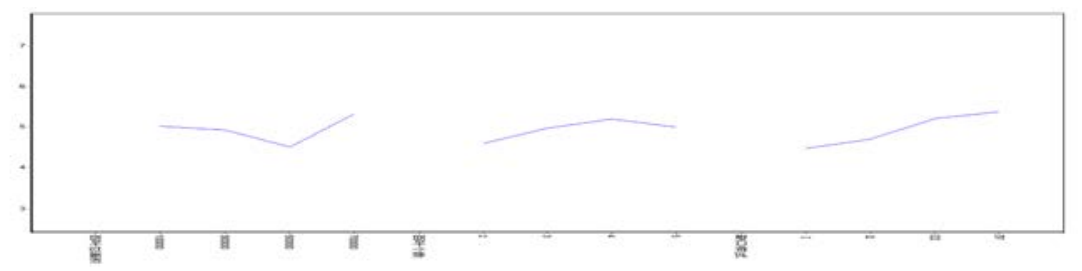

(a) the effect curve of drag coefficient

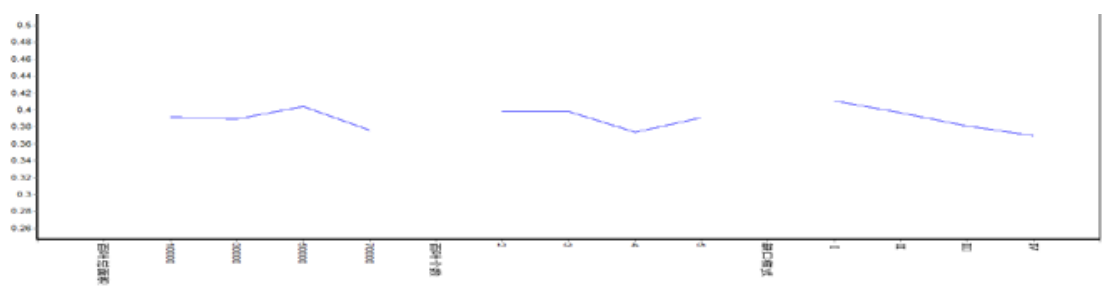

(b) the effect curve of Lift coefficient

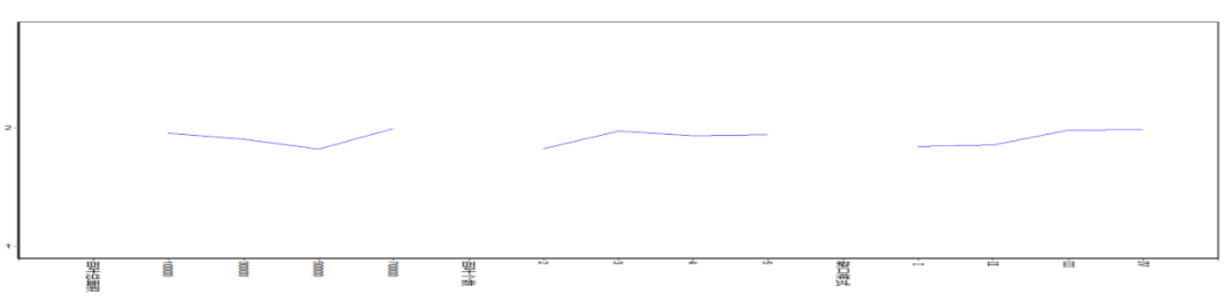

(c) the effect curve of Lift-drag ratio

Fig. 10 the effect curves 


\section{Calculation Result Analysis}

\subsection{Analysis of optimization schemes}

According the data of parameter design orthogonal table. Introducing the corresponding Model into STAR-CCM for flow Field and numerical Analysis, the data obtained are summarized to get the orthogonal test data.

From the effect curve(a),we can know, on the premise that the total gill area is the same,cdI $>$ cdII $>$ cdIII $>$ cdIV. It can be seen that the drag reduction effect of type IV rear edge notch style is obvious. However, on the premise of the same total leaf area, the negative lift provided by type IV is not the largest. It can be seen that type IV leeboards can reduce the induced drag of empennage. However, it will inevitably destroy the low pressure airflow at the bottom of the empennage and lose the pressure difference between the upper and lower wings, resulting in the decrease of the lift coefficient of the empennage and the decrease of the negative lift. From the effect curve(b),Subject to the same other factors,cdA1<cdA2<cdA3<cdA4,It can be seen that the larger "gill" and the leeboards edge notch area can reduce the drag caused by the wingtip vortex .However, too large a "gill" area can also reduce the negative lift on the empennage. It can be seen that drag and lift cannot be completely separated. The interaction between the two should be explored, so introduce the lift-drag ratio .Form(c),gill area is $70000 \mathrm{~mm} 2$; gill number is 4;notch at the back edge type is IV,existence of an optimal solution for lift-to-drag ratio.

flow field comparison

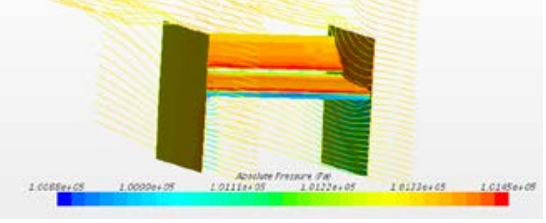

(a) Prototype empennage air streamline diagram

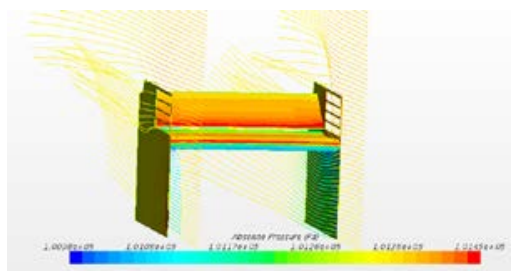

(b) Initial scheme air streamline diagram

Fig. 11 Air streamline diagram

\subsection{Flow field analysis of leeboards gill}

As shown in figure 11 contrast the three-dimensional air streamline diagram of prototype empennage(a) and initial design(b),it reflects the development and direction of air flow.Can be found in(b)The gill leads the high-pressure airflow to the outside of the leeboards and forms a towed airflow which weakens the vortex generated by the high-pressure flow through the wing tip.Among them, the gill has an obvious effect on the airflow guidance in the high pressure region, especially the airflow near the leeboards, which is the most prone to generate vortex, and it also provides a larger air flow rate for the flow to the leeboards edge notch to counterbalance the airflow that induces the vortex in the tip of the airfoil. You can kill two birds with one stone.Although the leeboards of(a) the prototype empennage is effectively isolated from the high and low pressure regions, the dowwash phenomenon after the airflow passes through the wing tip is obvious, and the induced vortex produces more additional induced drag.

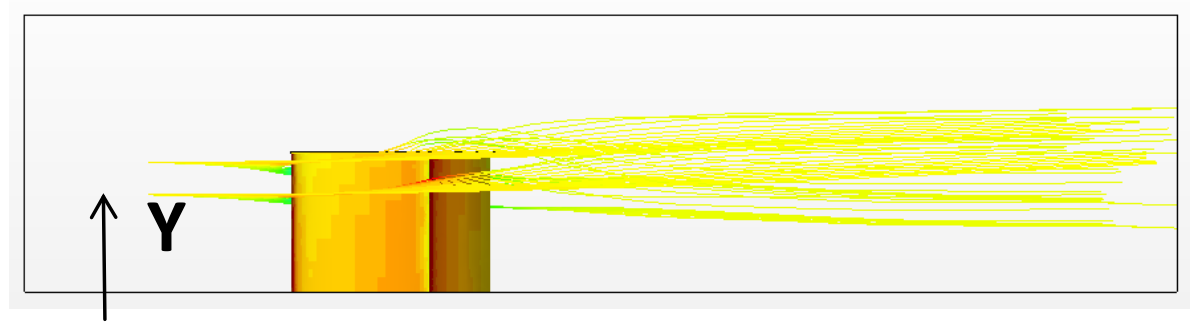

Fig. 12 overlooking diagram of initial square air flow line in front of empennage

From the angle of view from figure 12, the working principle of the gill and the flow of air from the gill can be analyzed more intuitively.The airflow from the "gill" flows to the low pressure region, 
producing a component in the Y- direction, and producing a counter-clockwise flow, at the same time the airflow flowing through the upper surface of the wing flows in the $\mathrm{Y}+$ direction, resulting in clockwise drag vortices. That is, induced vortex current.It can be seen that adding the "gill" structure leads the airflow from the high pressure area above the empennage to the low pressure area behind the empennage and produces counterclockwise airflow, so as to balance the induced vortex caused by the downwas phenomenon of the airfoil, so as to achieve the purpose of reducing drag.The three-dimensional diagram is shown in figure 13.

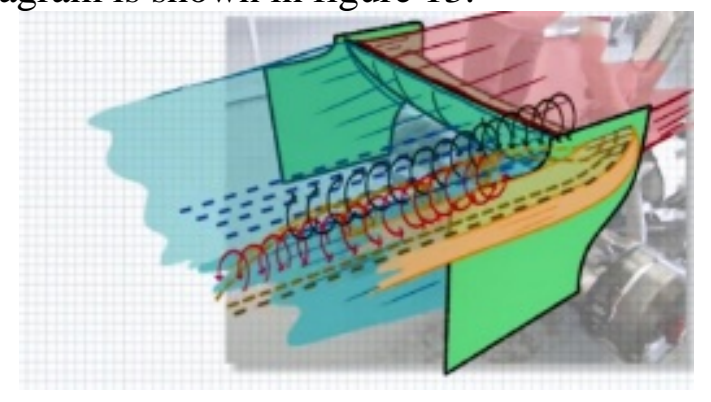

Fig. 13 vortex diagram of empennage

\subsection{Flow field analysis of the empennage leeboards edge notch}

In order to reveal the effect of the empennage edge notch flow field, the prototype empennage, initial scheme and optimization scheme were selected and compared.Figure (14) is a three-dimensional streamline developed at a series of horizontal fixed points in front of the empennage.Compare (a) and (b).It can be seen that compared with the prototype empennage, the initial scheme through the "gill" to guide the upper wing of the high pressure flow from the side, reducing the airfoil flow through the wing tip, reducing the generation of induced vortex. At the same time, some of the high pressure flow backward produced a weaker counterclockwise flow. However, there is not enough airflow deflection to weaken the vortex of the airfoil through the leeboards edge notch.Compare (b) and (c).Through the larger and deeper leeboards edge notch and the reasonable "gill" shape, the airflow from the "gill" can be more effectively guided to the rear of the empennage. Thus more counterclockwise airflow is produced to suppress the vortex at the tip of the empennage, and the induced drug of the empennage is reduced.Contrast the prototype empennage drag coefficient cd0.442; initial scheme drag coefficient cd0.377; optimized scheme drag coefficient cd0.358; It can be seen that the drag characteristics of the empennage are obviously optimized.The drag coefficient dropped by 14.47.It is shown that the induced drag has an obvious effect on the aerodynamic characteristics of the empennage under the special working conditions of FSAE. The optimization of the aerodynamic efficiency of the empennage by using the "gill" and the leeboards edge notch on the empennage is effective and effective.

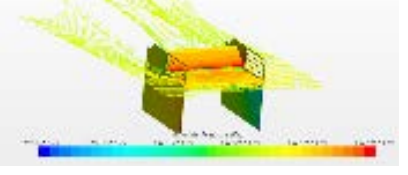

(a) air streamline diagram of prototype empennage

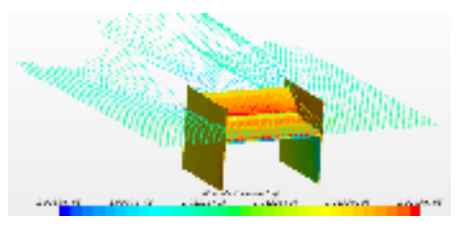

(b) air streamline diagram of initial scheme

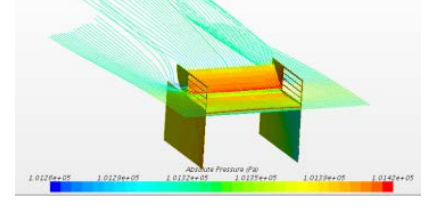

(c) air streamline diagram of optimized scheme

Fig. 14 Air streamline diagram 


\subsection{Flow Field Analysis of the influence of leeboards molding on negative lift of empennage}

According to the above research on the leeboards edge notch and gill, it can be concluded that the optimization of the leeboards can effectively reduce the induced drag of empennage.However, it is also found by orthogonal test that when the empennage is optimized by the above method, the negative lift will also be lost, so it is necessary to analyze the flow field.

Comparison of pressure clouds (a) in the prototype empennage and pressure clouds (b) in the optimization scheme in the same vertical direction,it reflect the pressure value and area of the upper and lower side of the empennage.It can be seen from the figure that the prototype empennage has a higher maximum pressure value of 226.30 pa, a lower minimum pressure value of -719.12 pa, and a larger area of high and low pressure region. By contrast, the maximum pressure value of the optimized scheme is 123.66 pa. the lowest pressure value is -326.16 pa. the area of high and low pressure region is even smaller. It can be seen that the "gill" structure destroys the high pressure area above the wing when reducing the induced drag. Similarly, the leeboards edge notch also leads the atmospheric air and part of the high pressure air to the bottom of the empennage, which destroys the pressure difference between the upper and lower sides of the wing and loses part of the lower pressure.As compared with 3.1.The results of the analysis are consistent. It can be seen that although part of lower pressure is lost in the optimization scheme of leeboards modeling, the lift-to-drag ratio is more excellent.The induced drag can be effectively reduced, and better aerodynamic efficiency can be obtained.

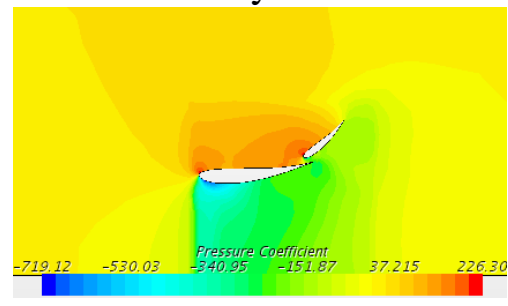

(a) Prototype empennage profile pressure cloud map

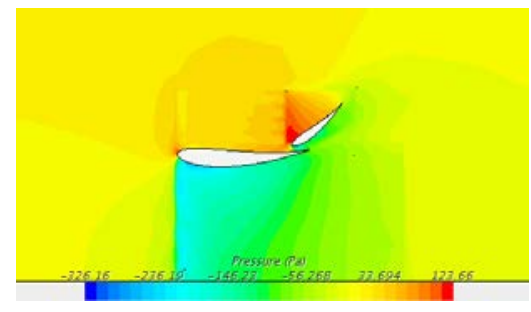

(b) optimized scheme profile pressure cloud map

Fig. 15 profile pressure cloud map

\section{Conclusion}

Through CATIA modeling and STAR-CCM analysis of different empennage design scheme, the following conclusions are obtained:

By adopting the "gill" structure of the leeboards of the empennage, the airflow in a part of the high pressure region can be directed to the outside of the leeboards and the rear part of the empennage to form a counterclockwise flow, thus weakening the vortex caused by the downwash phenomenon of the wing tip and reducing the induced drag.

The design of the empennage leeboards edge notch serves the design of the "gill". The purpose of the design is to make the airflow from the "gill" more efficient to produce the helical airflow which balances the induced vortex of the wing tip, to improve the aerodynamic performance of the empennage. The optimized drag coefficient CD was reduced by $14.47 \%$ from 0.442 to 0.358 .

The "gill" method and the leeboards edge notch method can effectively reduce the drag of the empennage, but inevitably destroy the upper and lower parts of the wing, and reduce the lower pressure of the empennage. It is found that in a certain range, the "gill" structure and the leeboards edge notch of the empennage have a limited effect on the lift coefficient CL, and maintain a relatively low drag coefficient cd. There exists an optimum rise-to-drag ratio, 5.684, which is $9.08 \%$ higher than that of prototype empennage5.211.

In this paper, only the area of "gill", the number of gill and the type of leeboards edge notch are analyzed to the aerodynamic characteristics of the end plate of the empennage, without considering the influence of the shape of the "gill", there is space with further optimization. 


\section{Acknowledgement}

National Natural Science Foundation of China (Grant No.51208238).

\section{References}

[1] Wan Juye. Model Optimization of Racing Car by Numerical Simulation [D]. Hefei University of Technology, 2014.

[2] Zeng Fei-yun. Aerodynamic Performance on Wonder FSC Racing Car [D]. Liaoning University of Technology, 2014.

[3] Hang Xiaoqiang, Wang Hongyu, Hou Wenbin. Design of an Aerodynamic Package for FSAE Racing Car and CFD Analysis [J]. Experiment Science and Technology, 2016, (1):3-7.

[4] Wu Chao, Deng Zhao wen, Wang Di. Performance Analysis on Aerodynamics Packages of FSC Racing Car [J]. Journal of Hubei University of Automotive Technology, 2015, Vol.29 No.2:28-32, 35.

[5] Shangzhou Xia. Numerical Simulation of the High Lift Airfoil [D]. Shenyang: Shenyang Institute of Aeronautical Engineering, 2006.

[6] Mao Xu, Wu Ningning. Aerodynamic Performance Improvement of a New Type Wing for Formula SAE Car [J]. Mechanical Science and Technology for Aerospace Engineering, 2014, 33 (9): 1397-1402

[7] Hu Li, Luo Shimin, Yang Qiliang, Yang Sheng. Desi gn of aerodynamic kit for the FSC racing car [J]. Journal of Wuhan University of Science and Technology, 2015

[8] Bai Qiu -yang. Combinational design and anal y sis of aerodynamics devices of FSAE racing car [J]. JOURNAL OF HEFEI UNIVERSITY OF TECHNOLOGY, 2016

[9] Yu Kainan Xie Shibin. Raer wing design and optimization for formula sae car based on CFD [J]. Journal of Mechanical \& Electrical Engineering, 2017, 35 (1): 16 - 21

[10] Gu Zhengqi. Automotive Aerodynamics [M]. China Communications Press, 2005

[11] Prandte L. An Introduction to Fluid Mechanics University [M].Science China Press, 1981

[12] Li Ling,Li Yuliang.Numerical Simulation of Turbulent Flow around Bluff Bodie0s Using the RNG k- $\varepsilon$ Turbulent Model [J].Advances In Water Science, 2000 